\title{
Influência dos Gases de Proteção na Soldagem do Aço UNS $\$ 31803$ com Arame E2209-T1/4 pelo Processo FCAW
}

\author{
Miguel Luiz Ribeiro Ferreira ${ }^{1}$, Claudio Alberto Fortes da Silva ${ }^{1}$, Juan Manuel Pardal ${ }^{1,2,3}$, Sérgio Souto Maior Tavares ${ }^{3}$ \\ 1 Universidade Federal Fluminense - UFF, Programa de Pós-graduação em Montagem Industrial, Niterói, RJ, Brasil. \\ 2 Universidade Federal Fluminense - UFF, Programa de Pós-graduação em Engenharia Mecânica - PGMEC, Niterói, RJ, Brasil. \\ 3 Centro Federal de Educação Celso Suckow, Programa de Pós-graduação em Engenharia Mecânica e Tecnologia de Materiais, \\ Rio de Janeiro, RJ, Brasil.
}

Recebido: 11 Abr., 2018

Aceito: 20 Ago., 2018

E-mail:miguelluiz@outlook.com (MLRF)
Resumo: O presente trabalho avalia a influência de adições entre 10 e $25 \%$ de $\mathrm{CO}_{2}$ como gases de proteção a base de argônio (Ar) nas propriedades mecânicas e resistência à corrosão de juntas soldadas pelo processo FCAW no aço inoxidável duplex (AID) UNS S31803 fazendo uso de arame eletrodo E2209T1-4. Sob estas condições o efeito da participação de 2\% de oxigênio $\left(\mathrm{O}_{2}\right)$ na mistura foi também levado em consideração. Ensaios mecânicos de tração e impacto Charpy, assim como de microdureza nas fases austenita e ferrita foram realizados em diversos locais das juntas assim produzidas. Paralelamente foram efetuados ensaios de corrosão para determinação da temperatura critica de pites (CPT) e perda de massa por unidade de área baseando-se nas especificações das normas ASTM G150 e G48, respectivamente. O estudo foi complementado com análises metalográficas mediante o emprego de diversos reagentes quantificando-se as fases presentes, assim como revelando características microestruturais nas condições supracitadas. Os valores das propriedades mecânicas obtidos nas juntas analisadas foram satisfatórios quando comparadas com valores normativos assim como de trabalhos publicados recentemente. Contudo, constatou-se ainda um aumento da CPT nas juntas soldadas com o emprego de gases com teores crescentes de $\mathrm{CO}_{2}$. Finalmente observou-se, que dentre as juntas soldadas estudadas, aquelas obtidas utilizando-se a mistura com composição de $73 \% \mathrm{Ar}+25 \% \mathrm{CO}_{2}+2 \% \mathrm{O}_{2}$, apresentou o melhor desempenho, tanto no que tange às propriedades mecânicas, quanto na resistência à corrosão. Os resultados obtidos permitem considerar a utilização de outras misturas gasosas na soldagem destes aços inoxidáveis com o processo FCAW, atém das indicadas normativamente, visando a grande demanda na construção e montagem de diversos componentes desta família de aço inoxidáveis na indústria offshore.

Palavras-chave: Aço inoxidável duplex; FCAW; Gases de proteção; Propriedades mecânicas; Resistência à corrosão.

\section{Influence of Shielding Gas in FCAW Process Welding of UNS S31803 with E2209-T1/4 Wire}

Abstract: The present work evaluates the influence of additions between 10 and $25 \%$ of $\mathrm{CO}_{2}$ in argon-based shielded gases on the mechanical properties and corrosion resistance of welded joints by the FCAW process in duplex stainless steel (DSS) UNS $\$ 31803$ using electrode wire E2209T1-4. Under these conditions the effect of the $2 \% \mathrm{O}_{2}$ addition in the mixture was also taken into account. Mechanical tensile test, Charpy toughness and microhardness in the austenite and ferrite phases were carried out in several places of the joints thus produced. Besides, corrosion tests were carried out to determine the critical pitting temperature (CPT) and mass loss per unit area based on the specifications of ASTM G150 and G48, respectively. The study was complemented with metallographic analyzes using several reagents, quantifying the present phases, as well as revealing microstructural characteristics in the studied conditions. The mechanical properties values obtained in the analyzed joints were satisfactory when compared with normative values as well in recently published works. However, it was also observed a CPT increase value in the joints welded with the use of gases with higher levels of $\mathrm{CO}_{2}$. Finally, it was observed that, among the welded joints studied, those obtained using the mixture with composition of $73 \% \mathrm{Ar}+25 \% \mathrm{CO}_{2}+2 \% \mathrm{O}_{2}$, presented the best performance, both with regard to mechanical properties and the corrosion resistance. The results allow determinates the use of other gaseous mixtures in the welding of DSS with the FCAW process, in addition to the normative one, in view of the great demand in the construction and assembly of several components of this stainless steel family in the offshore industry.

Key-words: Duplex stainless steel; FCAW; Shielding gases; Mechanical properties; Corrosion resistance.
Este é um artigo publicado em acesso aberto (Open Access)
sob a licença (reative Commons Attribution Non-Commercia que permite uso, distribuição e reprodução em qualquer meio, sem restriçōes desde que sem fins comerciais e que 0 trabalho original seja corretamente citado. 


\section{Introdução}

Os aços inoxidáveis duplex (AID) são ligas ferrosas produzidas com teores de Cr-Ni-Mo-N que permitem obter mediante tratamento termomecânico controlado uma fina microestrutura bifásica composta por frações semelhantes de ferrita $(\delta)$ e austenita $(\gamma)$. Apesar do seu custo mais elevado, em comparação aos aços inoxidáveis austeníticos (AIA), apresentam um melhor desempenho em termos de resistência mecânica e à corrosão em determinadas condições de serviço. Assim, em virtude da maior resistência mecânica e à corrosão, equipamentos construídos em AID são mais leves se comparados com aqueles construídos em AIA facilitando seu içamento e movimentação contribuindo ainda para a diminuição de tamanho dos suportes ou fundações, aumentando sua aplicação em estruturas que requeiram pouco peso, como em estruturas offshore. Porém, processos empregados na pré-fabricação e montagem de componentes, como a soldagem, podem provocar uma degradação dessas propriedades, comprometendo sua utilização [1-3].

Os grandes desafios tecnológicos na soldagem destes aços se centralizam no emprego de processos altamente produtivos tanto na pré-fabricação, quanto na montagem de componentes construídos em AID. Em relação à produção de spools e outros componentes de pequena espessura os processos de eletrodo revestido (SMAW) e TIG (GTAW) são empregados satisfatoriamente [4-6]. No que tange à pré-fabricação de componentes de grande espessura o processo de soldagem por arco submerso (SAW) ganhou recentemente notoriedade, assim como o uso do processo MIG (GMAW) com curto circuito controlado nos passes de raiz em substituição ao processo GTAW [7-9]. Entretanto, além da utilização do processo GMAW na montagem de componentes, procura-se viabilizar a utilização de processos que apresentem uma maior produtividade, principalmente, em locais com incidência de vento. Assim, sob estas condições, o emprego do processo de soldagem arame tubular (FCAW) torna-se promissor, apesar de problemas relatados em decorrência da diminuição da resistência mecânica e à corrosão da junta soldada, tais como, instabilidade do arco; formação de fases deletérias; perda de elementos de liga; desbalanceamento entre as fases ferrítica e austenítica; surgimento de poros vermiculares; inclusão de escória, dentre outros [9].

Na soldagem destes aços deve-se procurar a obtenção de juntas soldadas com balanços próximos entre as fases $\delta$ e $\gamma$ e ausência de fases deletérias ou terciárias, tais como chi $(\chi)$ e sigma ( $\sigma)$. Neste contexto, o emprego de velocidades de resfriamento muito elevadas conduzirá ao desenvolvimento de uma microestrutura, preponderantemente, ferrítica, contendo nitretos de cromo $\left(\mathrm{Cr}_{2} \mathrm{~N}\right)$ dispersos nesta fase. Já o emprego de altos valores de aporte de calor e/ou temperatura interpasse favorece a precipitação de $\gamma$, sendo a $\delta$ remanescente mais susceptível de formação de fases terciárias ou intermetálicas, pois a grande quantidade de elementos de liga na matriz ferrítica e alta taxa de difusão de elementos nesta fase em altas temperaturas tornam os AID suscetíveis à fragilização com a consequente perda das propriedades mecânicas. Neste sentido, merece destaque especial a fase sigma $(\sigma)$, por precipitar em maior proporção e ser mais estável termodinamicamente do que a fase ( $\chi$ ). A fase $\sigma$ é uma fase paramagnética de estrutura tetragonal rica em $\mathrm{Cr}$ e, quando presente em pequenas proporções, reduz de forma acentuada a tenacidade ao impacto e a resistência à corrosão [10-13]. Assim, os cuidados no controle da temperatura de interpasses e aporte de calor deverão assegurar que os ciclos térmicos desenvolvidos na soldagem, não permitam a ocorrência destes fenômenos. Neste sentido, recomenda-se um aporte térmico entre $0,5 \mathrm{~kJ} / \mathrm{mm}$ e 2,5 kJ/mm para a soldagem de aços duplex com temperatura interpasse que não ultrapasse os $150^{\circ} \mathrm{C}[14,15]$.

Nos processos GMAW e FCAW o tipo e composição do gás de proteção, com apenas um componente ou mistura de gases, permitem garantir a proteção da poça de fusão influenciando ainda dentre outros aspectos, no modo de transferência metálica, na velocidade de soldagem, na penetração na junta, nas propriedades mecânicas, na aparência e formato do cordão de solda e na geração de fumos e estabilidade do arco [14,16]. Uma atmosfera protetora adequada pode minimizar os problemas de soldagem já que a adição de uma pequena quantidade de um gás reativo, tal como o oxigênio, reduz a tensão superficial e promove a fluidez e molhabilidade sem desenvolver uma oxidação excessiva do metal de solda $[17,18]$. O tamanho das gotas é reduzido e o número de gotículas transferidas por unidade de tempo aumenta com o incremento do teor de oxigênio no gás de proteção. Por outro lado, o argônio puro, geralmente, é associado a uma elevada energia superficial, produzindo uma poça de fusão larga e que conduz a um cordão com alto reforço e face bastante convexa. Contudo, o gás de proteção interage com a poça de fusão e a adição de $\mathrm{CO}_{2}$ e $\mathrm{O}_{2}$ causa oxidação e, consequentemente, a perda de elementos de liga e a produção de inclusões no cordão de solda. A adição de $2 \%$ a $5 \%$ de oxigênio não tem um efeito significativo nas características do arco, mas afeta o gradiente de tensão superficial na poça de fusão acarretando a convecção do 
metal líquido na mesma [17]. Entretanto, adições de 7\% a 8\% de $\mathrm{O}_{2}$ aumentam a quantidade de escória e a sua aderência ao cordão de solda [13].

Na soldagem pelo processo GMAW diversos trabalhos dão grande importância à adição de nitrogênio $\left(\mathrm{N}_{2}\right)$ para se evitar a perda desse elemento do metal de solda a fim de obter uma partição satisfatória entre a $\delta$ e $\gamma$ em sua microestrutura. Porém, no processo FCAW a adição de nitrogênio no gás de proteção não possui um desempenho importante, pois a presença da escória que se solidifica a uma temperatura mais alta, atua como uma barreira contra a perda desse elemento $[8,19]$. Entretanto, a proporção de $\delta$ no metal de solda diminui com o incremento do percentual de $\mathrm{CO}_{2}$, já que difusão do $\mathrm{C}$, advindo da decomposição do gás, promove um aumento do níquel equivalente [20].

A abertura do arco e sua estabilidade também são em grande parte dependentes do potencial de ionização do gás de proteção selecionado [13]. Gases com potencial de ionização relativamente baixo, como por exemplo, o argônio, liberam elétrons mais facilmente, ajudando a iniciar e manter o arco com menor dificuldade. Entretanto, o uso do argônio puro no processo GMAW não é recomendado devido à instabilidade do arco elétrico e a obtenção de um perfil inadequado do cordão de solda [21]. A instabilidade do arco se deve ao fato de que os aços possuem uma característica de emissão não termiônica e adições de $\mathrm{CO}_{2}$ e ou $\mathrm{O}_{2}$, possibilitam o desenvolvimento de uma pequena camada de óxidos, facilitando a emissão de elétrons e melhorando a estabilidade do arco [14]. Arames tubulares concebidos para a soldagem de aço inoxidável, frequentemente, usam $\mathrm{CO}_{2}$ por que é mais econômico. Entretanto, também são muito utilizadas as misturas de $\mathrm{Ar}+\mathrm{CO}_{2}$, na faixa de 15 a $25 \%$ de $\mathrm{CO}_{2}$, que aumentam a produtividade, reduzem a distorção e propiciam maior controle da poça de fusão. Por outro lado, a norma AWS A5.22 prevê apenas a utilização de misturas binárias de Argônio e $\mathrm{CO}_{2}$ com determinadas composições para a soldagem de AID [22]. Portanto, neste trabalho foi estudado também a possibilidade de utilização de misturas binárias de Ar e $\mathrm{CO}_{2}$ com composições diferentes daquelas previstas pela norma AWS A5.22 e ternárias a base de $\mathrm{Ar}, \mathrm{CO}_{2}$ e $\mathrm{O}_{2}$.

A motivação deste estudo é atribuída à existência de poucos trabalhos sobre a influência dos gases de proteção nas propriedades das juntas soldadas pelo processo FCAW em AID. Além disso, a norma AWS A5.22 apenas contempla a utilização de gases de proteção na soldagem com este processo a misturas de Ar com até $20 \%$ de $\mathrm{CO}_{2}$. Assim, espera-se que este trabalho contribua para o desenvolvimento de outras composições de gases de proteção que possam ser utilizados na soldagem com o processo FCAW, bem como, na melhoria dos procedimentos de soldagem que aliem uma alta produtividade com elevadas propriedades mecânicas e resistência à corrosão das juntas assim produzidas.

\section{Materiais e Métodos}

No desenvolvimento deste trabalho que se baseou na influência dos gases de proteção na soldagem do AID pelo processo FCAW, utilizou-se como metal de base (MB) uma placa de AID UNS S31803 de $10 \mathrm{~mm}$ de espessura, cuja composição química é apresentada na Tabela 1. A geometria e dimensões do chanfro empregado são apresentadas na Figura 1. Vale ressaltar que, após a montagem de cada junta e, antes da execução da soldagem efetuou-se uma limpeza com acetona para remoção de gorduras e contaminantes que podem provocar o surgimento de porosidades e diminuição na resistência à corrosão [23].

Tabela 1. Composição química do metal de base (\% em peso). Fe balanço.

\begin{tabular}{ccccccccc}
\hline $\mathbf{C r}$ & $\mathbf{N i}$ & Mo & Mn & Si & N & C & P & S \\
22,000 & 5,500 & 3,100 & 0,700 & 0,800 & 0,18 & 0,020 & 0,003 & 0,010 \\
\hline
\end{tabular}

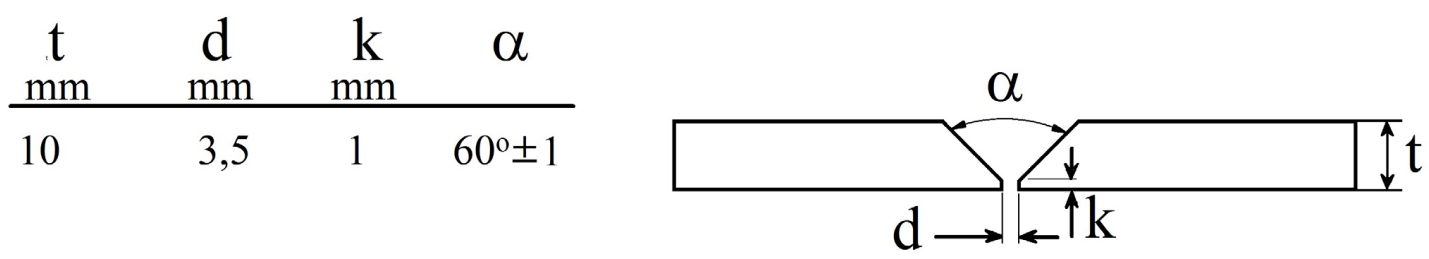

Figura 1. Geometria e dimensões do chanfro da junta soldada. 
Na soldagem pelo processo FCAW foram adotadas oito misturas gasosas como gás de proteção na produção de amostras, cujas identificações e composições são apresentadas na Tabela 2. Na produção destas misturas utilizou-se um misturador de gases modelo KM 20-200-3 ME fabricado pela empresa alemã Witt que forneceu uma vazão volumétrica de $12 \mathrm{l} / \mathrm{min}$ garantindo um erro menor que $1 \%$. Em todas as soldagens efetuadas foi empregado um arame consumível de soldagem E2209-T1/4 com 1,2 mm de diâmetro com núcleo fluxado rutílico. Na Tabela 3 são apresentados os requisitos de composição química do metal de adição de acordo com a norma AWS E2209-T1/4 e os valores típicos do metal depositado apresentada por Pettersson e Fager [23]. O processo de soldagem foi efetuado na posição plana através de uma fonte Powerwave S350 da Lincoln ${ }^{\circledR}$ adotando-se polaridade inversa (CC+), com uma distância do bico de contato à peça (DBCP) de aproximadamente $20 \mathrm{~mm}$, sendo a velocidade de alimentação do arame entre 38 e $42 \mathrm{~mm} / \mathrm{s}$. Vale ressaltar que não foi efetuada a purga na raiz durante o processo de soldagem de todas as amostras, entretanto uma contra solda foi realizada em todos os casos através do esmerilhamento prévio e limpeza apropriada da superfície da raiz. As Tabelas 4 e 5 apresentam os valores de tensão, corrente de soldagem, velocidade de avanço e aporte térmico, para cada passe de cada amostra produzida durante a soldagem considerando-se uma eficiência de energia de soldagem de 0,85 , ressaltando que em todos os casos a temperatura interpasse máxima foi de $100^{\circ} \mathrm{C}$.

Ao término da soldagem e antes da realização dos ensaios mecânicos foram efetuados sequencialmente ensaios de inspeção visual, de líquidos penetrantes e radiográficos com intuito de verificar descontinuidades nas juntas assim produzidas. $O$ intuito destas análises preliminares foi para determinar regiões isentas de descontinuidades na obtenção de corpos de provas e amostras para caracterização das propriedades mecânicas, microestrutura e resistência à corrosão de cada condição avaliada.

Em cada condição de estudo foi efetuado um ensaio de tração realizado à temperatura ambiente, aplicando-se uma velocidade de carregamento de 1,7 MPa/s em corpos de prova (cps) de dimensões $300 \mathrm{~mm} \times 25 \mathrm{~mm} \times 10 \mathrm{~mm}$ extraídos transversalmente à junta soldada baseando-se em especificações da ASME IX [24].

Tabela 2. Identificação e composição de cada amostra produzida.

\begin{tabular}{|c|c|}
\hline Identificação da Amostra (Id.) & Composição \\
\hline $90-10$ & $90 \% \operatorname{Ar} 10 \% \mathrm{CO}_{2}$ \\
\hline $85-15$ & $85 \% \operatorname{Ar} 15 \% \mathrm{CO}_{2}$ \\
\hline $80-20$ & $80 \% \operatorname{Ar} 20 \% \mathrm{CO}_{2}$ \\
\hline $75-25$ & $75 \% \operatorname{Ar} 25 \% \mathrm{CO}_{2}$ \\
\hline $88-10-2$ & $88 \% \operatorname{Ar} 10 \% \mathrm{CO}_{2} 2 \% \mathrm{O}_{2}$ \\
\hline $83-15-2$ & $83 \% \operatorname{Ar} 15 \% \mathrm{CO}_{2} 2 \% \mathrm{O}_{2}$ \\
\hline $78-20-2$ & $78 \% \operatorname{Ar} 20 \% \mathrm{CO}_{2} 2 \% \mathrm{O}_{2}$ \\
\hline $73-25-2$ & $73 \% \operatorname{Ar} 25 \% \mathrm{CO}_{2} 2 \% \mathrm{O}_{2}$ \\
\hline
\end{tabular}

Tabela 3. Composição química do metal de adição de acordo com a norma AWS E2209-T1/4 e valores típicos do metal depositado [23].

\begin{tabular}{ccc}
\hline$\%$ em Peso & Requisitos da AWS E2209-T1/4 & Resultados típicos [20] \\
C & 0,04 máx. & 0,03 \\
Mn & 0,5 a 2,0 & 1,20 \\
Si & 1,00 máx. & 0,70 \\
S & 0,02 máx. & $<0,01$ \\
P & 0,030 máx. & 0,02 \\
Cr & 21,5 a 24,0 & 23,0 \\
$\mathrm{Ni}$ & 8,5 a 10,0 & 9,20 \\
Mo & 2,8 a 4,0 & 3,10 \\
Cu & 0,3 máx. & 0,10 \\
N & 0,08 a 0,20 & 0,12 \\
\hline
\end{tabular}


Tabela 4. Parâmetros de soldagem e aporte térmico estimado para as misturas (100-X)\%Ar- $\mathrm{X} \% \mathrm{CO}_{2}$.

\begin{tabular}{|c|c|c|c|c|c|c|c|}
\hline Id. & Passe & Camada & $\begin{array}{c}\text { Tensão } \\
\text { (V) }\end{array}$ & $\begin{array}{l}\text { Corrente } \\
\text { (A) }\end{array}$ & $\begin{array}{l}\text { Velocidade } \\
\text { (cm/min) }\end{array}$ & $\begin{array}{c}\text { Aporte Térmico } \\
(\mathrm{kJ} / \mathrm{mm})\end{array}$ & $\begin{array}{l}\text { Aporte Térmico } \\
\text { Médio }(\mathrm{kJ} / \mathrm{mm})\end{array}$ \\
\hline \multirow{6}{*}{$90-10$} & 1 & 1 & 20 & 105 & 11 & 1,02 & \multirow{6}{*}{$0,81 \pm 0,28$} \\
\hline & 2 & 2 & 24 & 152 & 15 & 1,22 & \\
\hline & 3 & 3 & 26 & 147 & 31 & 0,62 & \\
\hline & 4 & 3 & 24 & 157 & 37 & 0,52 & \\
\hline & 5 & 3 & 24 & 165 & 36 & 0,56 & \\
\hline & Contra solda & --- & 24 & 162 & 22 & 0,90 & \\
\hline \multirow{5}{*}{$85-15$} & 1 & 1 & 21 & 103 & 12 & 0,88 & \multirow{5}{*}{$0,77 \pm 0,18$} \\
\hline & 2 & 2 & 24 & 160 & 26 & 0,76 & \\
\hline & 3 & 2 & 24 & 159 & 33 & 0,60 & \\
\hline & 4 & 2 & 24 & 168 & 34 & 0,61 & \\
\hline & Contra solda & --- & 24 & 160 & 19 & 1,02 & \\
\hline \multirow{7}{*}{$80-20$} & 1 & 1 & 21 & 104 & 9 & 1,24 & \multirow{7}{*}{$0,76 \pm 0,18$} \\
\hline & 2 & 2 & 24 & 155 & 27 & 0,70 & \\
\hline & 3 & 3 & 24 & 167 & 30 & 0,69 & \\
\hline & 4 & 4 & 24 & 164 & 32 & 0,64 & \\
\hline & 5 & 4 & 24 & 163 & 36 & 0,56 & \\
\hline & 6 & 4 & 24 & 157 & 33 & 0,59 & \\
\hline & Contra solda & --- & 24 & 162 & 23 & 0,88 & \\
\hline \multirow{6}{*}{$75-25$} & 1 & 1 & 21 & 102 & 10 & 1,13 & \multirow{6}{*}{$0,81 \pm 0,24$} \\
\hline & 2 & 2 & 24 & 160 & 20 & 1,01 & \\
\hline & 3 & 3 & 24 & 153 & 30 & 0,64 & \\
\hline & 4 & 3 & 24 & 153 & 33 & 0,58 & \\
\hline & 5 & 3 & 25 & 138 & 31 & 0,57 & \\
\hline & Contra solda & --- & 24 & 157 & 21 & 0,95 & \\
\hline
\end{tabular}

Tabela 5. Parâmetros de soldagem e aporte térmico estimado para as misturas $(98-\mathrm{X}) \% \mathrm{Ar}+\mathrm{X} \% \mathrm{CO}_{2}+2 \% \mathrm{O}_{2}$.

\begin{tabular}{|c|c|c|c|c|c|c|c|}
\hline Id. & Passe & Camada & $\begin{array}{c}\text { Tensão } \\
\text { (V) }\end{array}$ & $\begin{array}{l}\text { Corrente } \\
\text { (A) }\end{array}$ & $\begin{array}{c}\text { Velocidade } \\
\text { (cm/min) }\end{array}$ & $\begin{array}{c}\text { Aporte Térmico } \\
(\mathrm{kJ} / \mathrm{mm})\end{array}$ & $\begin{array}{l}\text { Aporte Térmico } \\
\text { Médio }(\mathrm{kJ} / \mathrm{mm})\end{array}$ \\
\hline \multirow{6}{*}{$88-10-2$} & 1 & 1 & 21 & 102 & 12 & 0,90 & \multirow{6}{*}{$0,68 \pm 0,19$} \\
\hline & 2 & 2 & 24 & 151 & 21 & 0,90 & \\
\hline & 3 & 3 & 24 & 162 & 34 & 0,59 & \\
\hline & 4 & 3 & 24 & 152 & 32 & 0,59 & \\
\hline & 5 & 3 & 24 & 153 & 28 & 0,68 & \\
\hline & Contra solda & --- & 24 & 162 & 48 & 0,42 & \\
\hline \multirow{6}{*}{$83-15-2$} & 1 & 1 & 21 & 102 & 12 & 0,90 & \multirow{6}{*}{$0,68 \pm 0,19$} \\
\hline & 2 & 2 & 24 & 151 & 21 & 0,90 & \\
\hline & 3 & 3 & 24 & 162 & 34 & 0,59 & \\
\hline & 4 & 3 & 24 & 152 & 32 & 0,59 & \\
\hline & 5 & 3 & 24 & 153 & 28 & 0,68 & \\
\hline & Contra solda & --- & 24 & 162 & 48 & 0,42 & \\
\hline \multirow{6}{*}{$78-20-2$} & 1 & 1 & 21 & 100 & 9 & 1,24 & \multirow{6}{*}{$0,81 \pm 0,35$} \\
\hline & 2 & 2 & 24 & 149 & 15 & 1,22 & \\
\hline & 3 & 3 & 24 & 149 & 28 & 0,65 & \\
\hline & 4 & 3 & 25 & 146 & 29 & 0,64 & \\
\hline & 5 & 3 & 25 & 140 & 25 & 0,73 & \\
\hline & Contra solda & --- & 24 & 164 & 58 & 0,35 & \\
\hline \multirow{6}{*}{$73-25-2$} & 1 & 1 & 22 & 100 & 10 & 1,12 & \multirow{6}{*}{$0,90 \pm 0,27$} \\
\hline & 2 & 2 & 25 & 140 & 15 & 1,20 & \\
\hline & 3 & 3 & 25 & 144 & 32 & 0,57 & \\
\hline & 4 & 3 & 24 & 149 & 25 & 0,73 & \\
\hline & 5 & 3 & 24 & 147 & 28 & 0,66 & \\
\hline & Contra solda & --- & 24 & 164 & 19 & 1,09 & \\
\hline
\end{tabular}


Avaliou-se a tenacidade ao impacto fazendo uso de um pêndulo universal Charpy, à temperatura aproximada de $-46^{\circ} \mathrm{C}$, em $24 \mathrm{cps}$ de tamanho reduzido de $55 \mathrm{~mm} \times 10 \mathrm{~mm} \times 7,5 \mathrm{~mm}$ [25], retirados transversalmente na junta soldada. $O$ entalhe foi realizado no centro do metal de solda (CMS), na zona de ligação ou linha de fusão (LF) e a $2 \mathrm{~mm}$ da LF na direção da ZTA, totalizando $3 \mathrm{cps}$ por cada condição. Os valores de energia absorvida foram corrigidos segundo a norma ASTM A-370 segundo a Equação 1.

$$
E a_{10}=1,35 . E a_{7,5}-0,05
$$

onde: $\mathrm{Ea}_{10}=$ Energia absorvida pelo corpo de prova padrão $(55 \mathrm{~mm} \times 10 \mathrm{~mm} \times 10 \mathrm{~mm}) ; \mathrm{Ea}_{7,5}=$ Energia absorvida pelo corpo de prova de tamanho reduzido $(55 \mathrm{~mm} \times 10 \mathrm{~mm} \times 10 \mathrm{~mm}$ ).

Análises de microdureza Vickers foram realizadas com carga de $0,98 \mathrm{~N}$ durante 15 segundos em cada fase tanto no metal de solda (MS) como na zona termicamente afetada (ZTA) para comparação com o metal de base (MB) de cada amostra estudada. Os ensaios de microdureza foram precedidos de análise metalográfica da junta soldada, preparada através de lixamento e polimento convencionais, com posterior aplicação do reagente Beraha.

A avaliação microestrutural da junta soldada foi realizada através de microscopia ótica em amostras do metal de base, solda e ZTA atacadas com o reagente Beraha e KOH. As quantificações das fases $\delta$ e $\gamma$ em diferentes regiões do metal de solda foram realizadas através do programa Image Tool v.3.0 [26], com média de 10 (dez) imagens por região e com diferentes aumentos metalográficos.

As análises eletroquímicas por estimativa da temperatura crítica de pites (CPT) de cada região da junta soldada foram efetuadas conforme a norma ASTM G150 [27], através de um potenciostato galvanostato $\mu$ Autolab ${ }^{\circledR}$ Type III e uma célula eletroquímica, em banho maria, contendo o eletrodo de trabalho, o contra-eletrodo de platina e o eletrodo de referência de calomelano saturado (SCE).

Os eletrodos de trabalho foram fabricados por fixação das amostras a um fio rígido de cobre (Cu) através de um rasgo em cada amostra, possibilitando, deste modo, a inserção do fio sob pressão. Foram analisadas as regiões da ZTA e MS de cada condição de estudo e comparadas ao MB. Em seguida, estes eletrodos foram embutidos em resina de cura a frio. A superfície de cada amostra em contato com o eletrólito foi preparada até a lixa de granulometria 400. De modo a evitar a corrosão por frestas, as laterais e vértices do eletrodo em contato com a resina foram recobertos com verniz. Sob estas condições realizou-se o ensaio em triplicata para cada região da junta soldada nas diversas condições de estudo fazendo uso de uma solução aerada de $1 \mathrm{M} \mathrm{NaCl}$. Assim, elevou-se a temperatura do ensaio a uma taxa de $4{ }^{\circ} \mathrm{C}$ por minuto a partir de $10{ }^{\circ} \mathrm{C}$, mantendo-se um potencial constante de $700 \mathrm{mV}$ no eletrodo de trabalho em relação ao eletrodo de referência (SCE) até a densidade de corrente ultrapassar $100 \mu \mathrm{A} / \mathrm{cm}^{2}$, pelo período mínimo de 60 (sessenta) segundos determinando desta maneira a CPT.

Ensaios de imersão por perda de massa foram realizados em cada junta soldada baseando-se na metodologia $A$ da norma ASTM G48 [28]. Inicialmente, foi realizada uma decapagem em solução de $20 \% \mathrm{HNO}_{3}+5 \% \mathrm{HF}$ por 5 minutos seguidos de um tempo de passivação de 24 horas de cada amostra seguido da obtenção da sua superfície e massa. As amostras foram imersas por 72 horas em uma solução aquosa contendo $100 \mathrm{~g}$ de cloreto férrico hexa-hidratado $\left(\mathrm{FeCl}_{3} 6 \mathrm{H}_{2} \mathrm{O}\right)$ em $900 \mathrm{ml}$ de $\mathrm{H}_{2} \mathrm{O}$ à temperatura de $22 \pm 2{ }^{\circ} \mathrm{C}$. Após o período de tempo de imersão especificado procedeu-se à limpeza, secagem e pesagem final de cada amostra analisada por condição de ensaio. Cabe ressaltar, que após este ensaio algumas amostras foram lixadas e polidas conforme procedimento metalográfico convencional efetuando-se, logo em seguida, um ataque eletrolítico com uma solução aquosa contendo $10 \%$ de ácido oxálico aplicando-se uma tensão de $3 \mathrm{~V}$ durante um intervalo de 30 segundos para caracterização por microscopia óptica (MO) de modo a evidenciar o motivo do decréscimo da resistência à corrosão em determinadas condições de estudo.

\section{Resultados e Discussão}

A Figura 2 exibe o percentual de ferrita em função do teor de $\mathrm{CO}_{2}$ em misturas binárias (100-X)\% $\mathrm{Ar}+\mathrm{X} \% \mathrm{CO}_{2}$. Na mesma se observa que o teor desta fase não experimenta mudanças significativas tanto na raiz e acabamento do metal de solda quanto na ZTA, embora se perceba apenas uma leve diminuição na ZTA, para as composições com $20 \%$ e $25 \%$ de $\mathrm{CO}_{2}$. Este fato pode ter origem no maior poder emissivo do gás afetando o rendimento térmico do processo, já que os valores de aporte de calor estimados para essas condições, apresentados na Tabela 4 são semelhantes. No entanto, vale ressaltar, que apenas os teores de ferrita na ZTA das condições 80-20 e 75-25 situam-se 
dentro do valor máximo de $70 \%$ especificado pela NORSOK M 601 [29]. No que tange ao metal de solda os teores de ferrita se situam com valores mais próximos do metal de base, ou seja, dentro da faixa ideal que promove a partição adequada dos elementos de liga entre ambas as fases. Este fato é principalmente atribuído ao emprego do consumível E2209-T1/4 que possui 9\% de níquel favorecendo deste modo a uma maior formação de austenita. Entretanto, quando comparado o comportamento entre a raiz e o acabamento, se observa uma menor proporção de ferrita na raiz, a qual se atribui, principalmente, à formação da austenita secundária devido aos sucessivos reaquecimentos que esta região experimenta. Em relação à influência do $\mathrm{CO}_{2}$, não foram observadas diferenças significativas no teor percentual de ferrita. Entretanto, cabe destacar, a possibilidade da ocorrência da influência da dissociação do $\mathrm{CO}_{2}$, a qual poderá ter como consequência a ação do carbono livre na estabilização da fase austenítica. A Figura 3 exibe as microestruturas para condições 90-10 e 20-80 onde se verifica as características microestruturais supracitadas.

A Figura 4 exibe o percentual de ferrita em função do teor de $\mathrm{CO}_{2}$ em misturas ternárias $(100-\mathrm{X}-2) \% \mathrm{Ar}+\mathrm{X} \% \mathrm{CO}_{2}+2 \% \mathrm{O}_{2}$. Assim como quando se utiliza misturas binárias, se denota uma maior proporção de ferrita na ZTA e valores próximos entre o metal de base e o metal de solda. A Figura 5 exibe as microestruturas para condições 78-20-2 e 73-25-2 onde se verifica essas características microestruturais. Entretanto, observou-se para a mistura com $20 \%$ $\mathrm{CO}_{2}$, uma maior proporção de ferrita em relação aos resultados obtidos com as outras misturas. Contudo, apesar de não serem observadas mudanças no aporte térmico na Tabela 5, este efeito poderia ser em parte atribuído ao oxigênio no gás de proteção, dado que quando analisadas condições homólogas para as misturas ternárias e

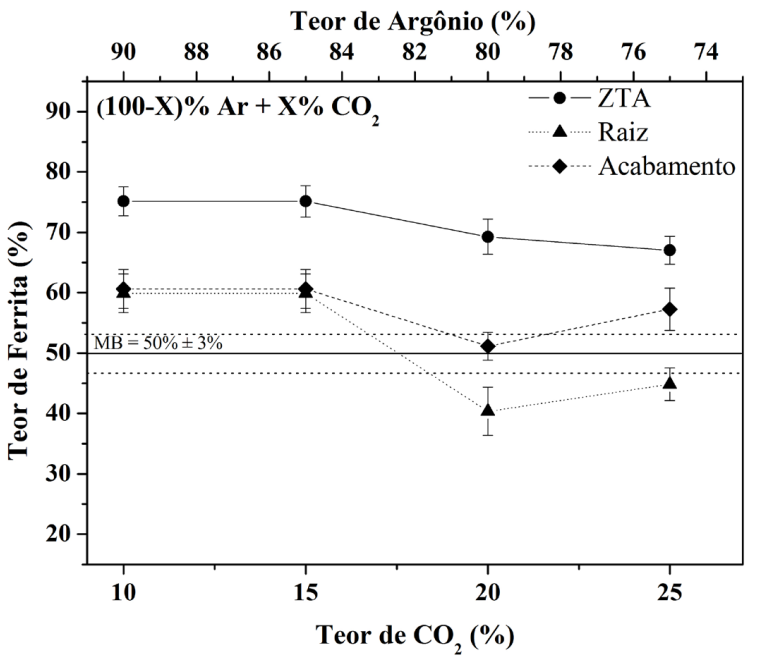

Figura 2. Percentual de ferrita em função do teor de $\mathrm{CO}_{2}$ em misturas binárias $(100-\mathrm{X}) \% \mathrm{Ar}+\mathrm{X} \% \mathrm{CO}_{2}$.
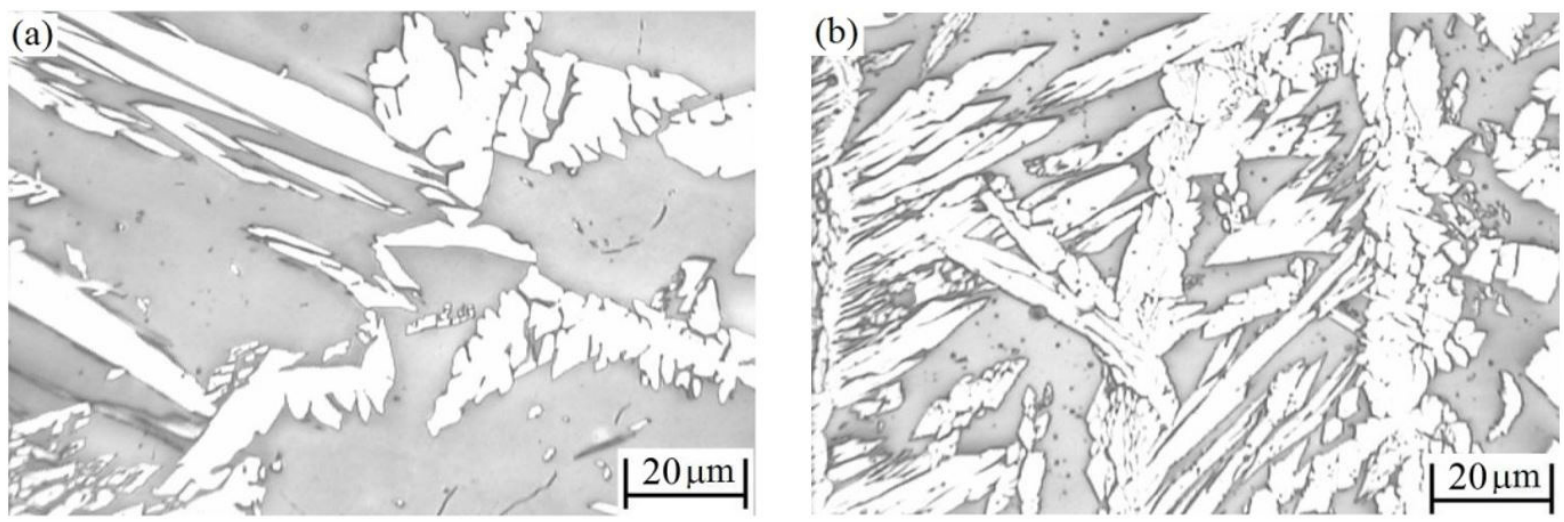

Figura 3. Microestruturas de regiões características das juntas soldadas com misturas binárias. (a) ZTA, 90-10; (b) Raiz, 80-20. 


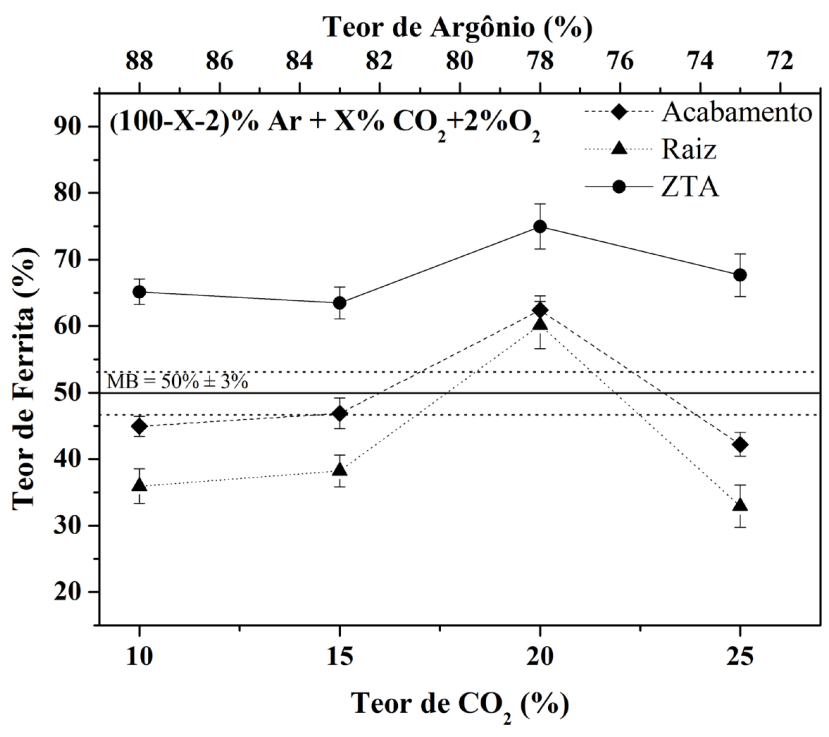

Figura 4. Percentual de ferrita em função do teor de $\mathrm{CO}_{2}$ em misturas ternárias $(100-\mathrm{X}-2) \% \mathrm{Ar}+\mathrm{X} \% \mathrm{CO}_{2}+2 \% \mathrm{O}_{2}$.
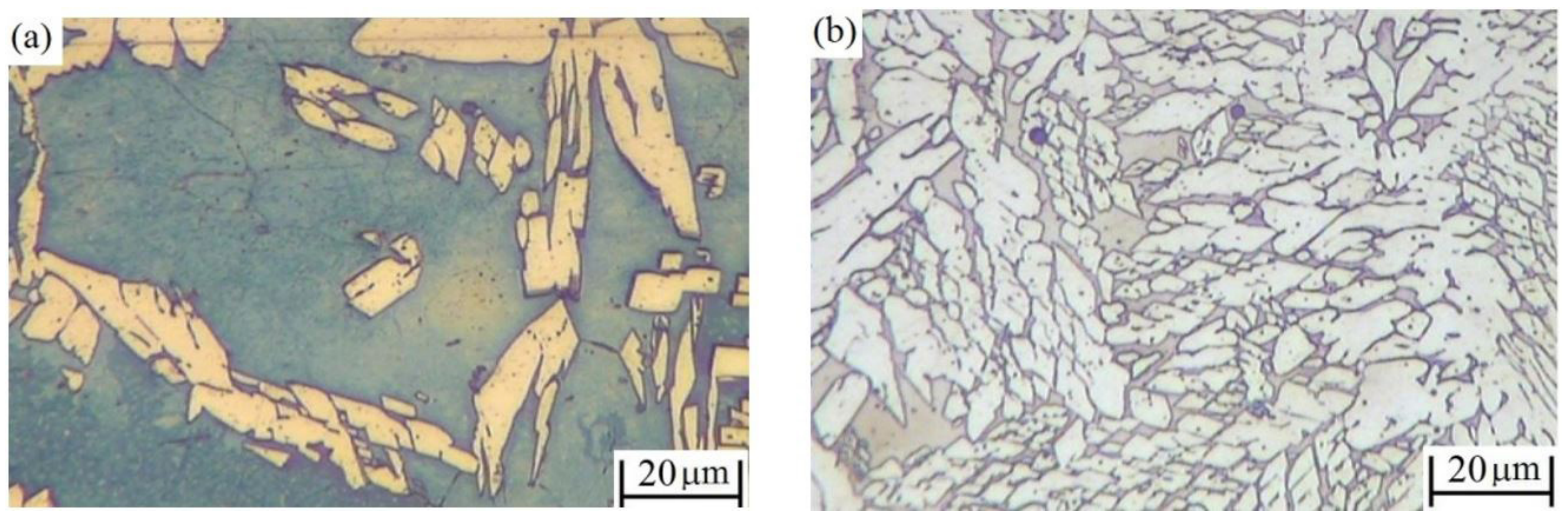

Figura 5. Microestruturas de regiões características das juntas soldadas com misturas ternárias. (a) ZTA, 78-20-2; (b) Raiz, -73-25-2.

binárias este efeito não foi detectado. Assim, pode existir a interação do oxigênio e o carbono livre advindo do $\mathrm{CO}_{2}$ responsável pela estabilização da austenita favorecendo, deste modo, indiretamente, o aumento do percentual de ferrita, embora este fato requeira uma análise mais aprofundada, já que o mesmo não se verifica para a mistura ternária com $25 \%$ de $\mathrm{CO}_{2}$.

No que concerne à caracterização por microdureza, em geral se observa, no metal de solda, um comportamento próximo ao do metal de base, tanto da ferrita, quanto da austenita, como pode ser visto nas Figuras 6 e 7. Entretanto, um fato bastante interessante é detectado na condição 75-25 onde, tanto a fase ferrítica, quanto a austenítica, exibem picos de dureza de $339 \mathrm{HV}$ e $324 \mathrm{HV}$, respectivamente. Este comportamento, que deve ser estudado com maior profundidade, pode ser atribuído a efeitos concomitantes de um maior refino microestrutural da fase ferrítica, produto da precipitação da austenita secundária a partir do nitreto de cromo, que por sua vez possui diferenças na dureza com aquela oriunda do arrefecimento em temperatura mais elevadas. Além disso, pode haver um efeito de enrijecimento por solução sólida do carbono na fase austenítica proveniente do gás de proteção, entretanto, este efeito no metal de solda deverá ser estudado exaustivamente em um trabalho futuro por meio de microscopia eletrônica de varredura mediante emprego de microanálise elementar por WDS na detecção de elementos leves, tais como carbono e nitrogênio. Por outro lado, nas Figuras 8 e 9, pode-se observar que com a adição de $\mathrm{O}_{2}$ as durezas de ambas as fases não se alteram com o teor de $\mathrm{CO}_{2}$. 


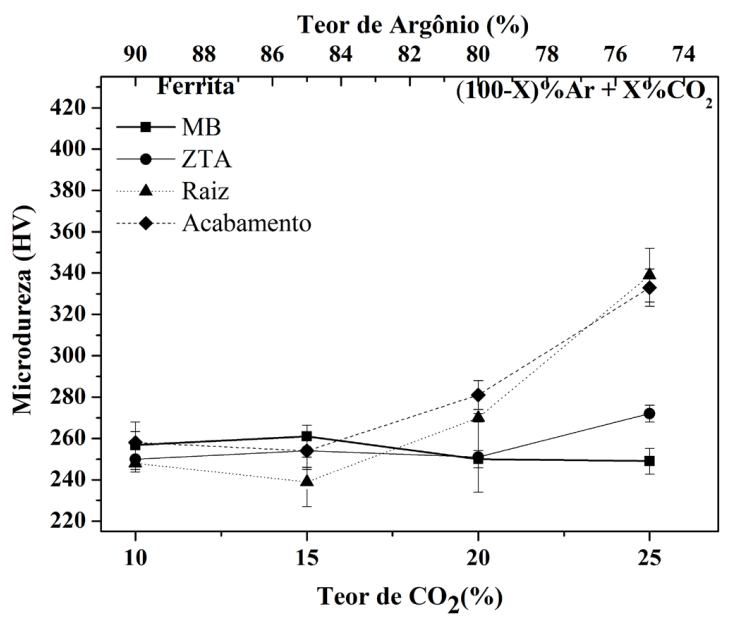

Figura 6. Valores de microdureza Vickers na fase ferrita em função do teor de $\mathrm{CO}_{2}$ em misturas binárias $(100-\mathrm{X}) \% \mathrm{Ar}+\mathrm{X} \% \mathrm{CO}_{2}$.

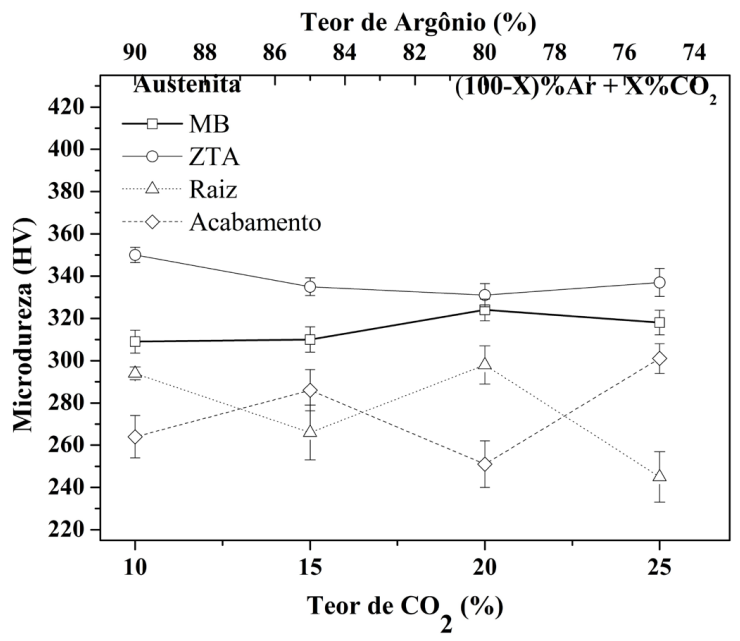

Figura 7. Valores de microdureza Vickers na fase austenita em função do teor de $\mathrm{CO}_{2}$ em misturas binárias $(100-\mathrm{X}) \% \mathrm{Ar}+\mathrm{X} \% \mathrm{CO}_{2}$.

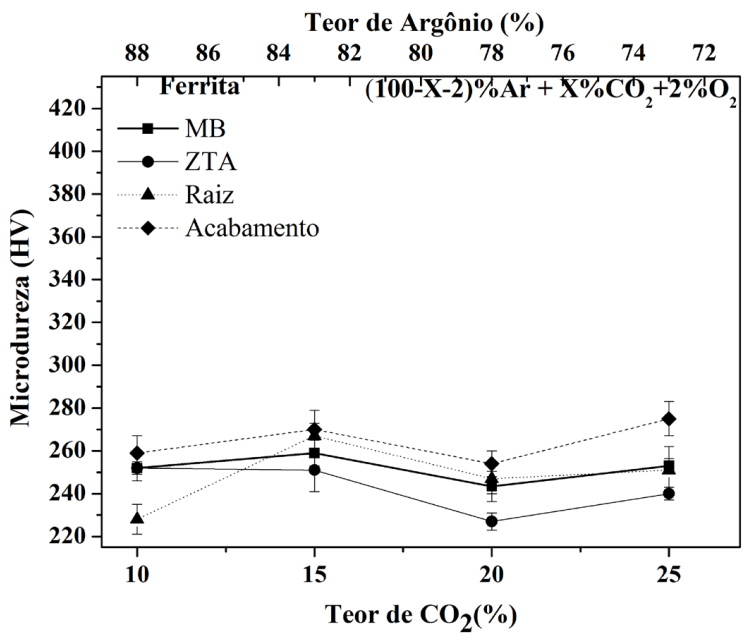

Figura 8. Valores de microdureza Vickers na fase ferrita em função do teor de $\mathrm{CO}_{2}$ em misturas ternárias $(100-\mathrm{X}-2) \% \mathrm{Ar}+\mathrm{X} \% \mathrm{CO}_{2}+2 \% \mathrm{O}_{2}$. 


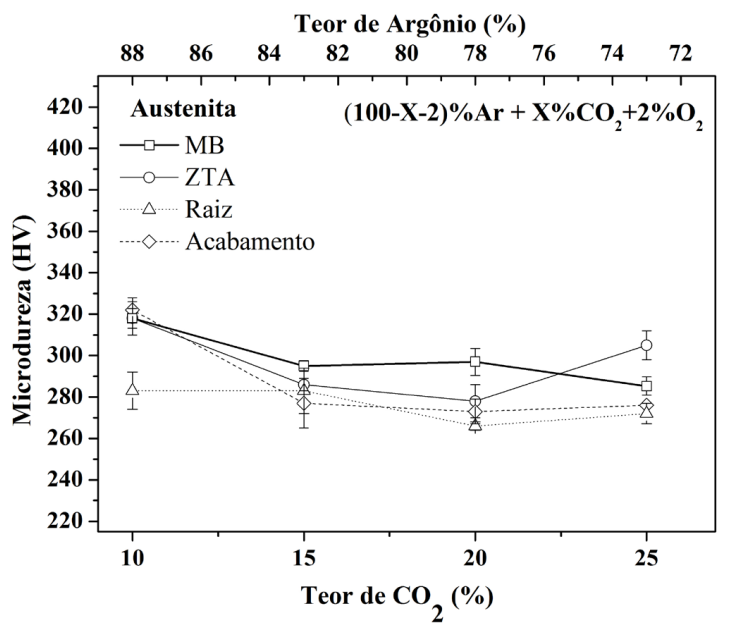

Figura 9. Valores de microdureza Vickers na fase austenita em função do teor de $\mathrm{CO}_{2}$ em misturas ternárias $(100-\mathrm{X}-2) \% \mathrm{Ar}+\mathrm{X} \% \mathrm{CO}_{2}+2 \% \mathrm{O}_{2}$.

Na Tabela 6 se observa a influência da utilização dos gases de proteção estudados na resistência mecânica da junta soldada, atentando-se ao fato de que todas as fraturas ocorreram de forma dúctil no metal de base, tal como observado na Figura 10a para o cp na condição 75-25. Neste contexto, na Figura 10b se observa a superfície de fratura com aspecto fosco e claros sinais de deformação plástica com uma região preponderantemente cisalhante, apresentando uma redução de área de 50,6\%. Da mesma forma, se detectou o mesmo comportamento para os corpos de prova ensaiados em juntas soldadas utilizando o gás de proteção com $2 \%$ de $\mathrm{O}_{2}$.

Tabela 6. Valores das propriedades mecânicas obtidas mediante ensaio de tração para cada composição de gás de proteção estudada.

\begin{tabular}{ccccc}
\hline $\begin{array}{c}\text { Condição de } \\
\text { Soldagem Id. CP }\end{array}$ & $\begin{array}{c}\text { Limite de } \\
\text { Escoamento (MPa) }\end{array}$ & $\begin{array}{c}\text { Limite de Resistência } \\
\text { (MPa) }\end{array}$ & $\begin{array}{c}\text { Alongamento } \\
\text { (\%) }\end{array}$ & $\begin{array}{c}\text { Redução de Área } \\
\text { (\%) }\end{array}$ \\
$90-10$ & 575 & 735 & 14,5 & 21,4 \\
$85-15$ & 560 & 750 & 32,5 & 55,0 \\
$80-20$ & 575 & 760 & 30,0 & 51,3 \\
$75-25$ & 570 & 770 & 28,0 & 50,6 \\
$88-10-2$ & 570 & 750 & 30,5 & 55,3 \\
$83-15-2$ & 575 & 755 & 28,0 & 48,3 \\
$78-20-2$ & 540 & 760 & 28,0 & 56,6 \\
$73-25-2$ & 565 & 780 & 31,0 & 57,1 \\
\hline
\end{tabular}
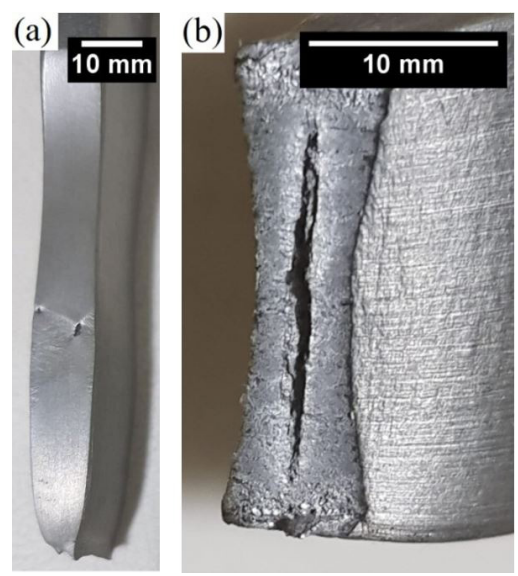

Figura 10. Imagens da fratura do corpo de prova da condição 75-25 no teste de tração. (a) Fratura do cp no MB; (b) Aspecto da fratura do cp após ensaio de tração. 
Os valores de tenacidade obtidos com os corpos de prova reduzidos e os valores corrigidos pela norma ASTM A 370 com a Equação1obtida por regressão linear são apresentados na Tabela 7 [30]. Como se pode observar, os valores de tenacidade não apresentam relação com a quantidade de $\mathrm{CO} 2$ ou $\mathrm{O} 2$ na mistura gasosa. No centro do cordão de solda os valores de energia absorvida são menores, porém, nos corpos de prova com dimensões reduzidas os resultados superaram o valor mínimo requerido de $27 \mathrm{~J}$ que é a energia tipicamente recomendada pelo código ASME como valor mínimo para estes aços [24].

Tabela 7. Valores de tenacidade ao impacto levantados em cada local da junta soldada. Valores equivalentes comparados com CPS de tamanho padrão se baseando na especificação ASTM A370 [30].

\begin{tabular}{|c|c|c|c|c|c|c|}
\hline \multirow{2}{*}{$\begin{array}{l}\text { Condição de } \\
\text { Soldagem } \\
\text { Id. CP }\end{array}$} & \multicolumn{2}{|c|}{ Centro do Metal de Solda (J) } & \multicolumn{2}{|c|}{ Linha de Fusão $(\mathrm{J})$} & \multicolumn{2}{|c|}{ Linha de Fusão + $2 \mathrm{~mm}(\mathrm{~J})$} \\
\hline & Valor medido & Valor corrigido & Valor medido & Valor corrigido & Valor medido & Valor corrigido \\
\hline $90-10$ & 34,3 & 46,2 & 70,7 & 95,1 & 141,5 & --- \\
\hline $85-15$ & 34,5 & 46,4 & 67,9 & 91,4 & 204,0 & --- \\
\hline $80-20$ & 30,3 & 40,8 & 65,9 & 88,7 & 116,4 & --- \\
\hline $75-25$ & 34,1 & 45,9 & 44,7 & 60,1 & 193,7 & --- \\
\hline $88-10-2$ & 31,6 & 42,5 & 97,2 & 130,8 & 164,6 & --- \\
\hline $83-15-2$ & 34,1 & 45,9 & 73,5 & 98,9 & 121,7 & --- \\
\hline $78-20-2$ & 33,9 & 45,6 & 36,5 & 49,0 & 133,1 & --- \\
\hline $73-25-2$ & 34,3 & 46,2 & 67,7 & 91,0 & 185,8 & -- \\
\hline
\end{tabular}

Nas Figuras 11 e 12 é possível observar uma comparação entre os resultados dos ensaios de impacto obtidos neste trabalho com aqueles obtidos por Pardal et al. [31] quando aplicados os processos GTAW e SAW. Na mistura binária os valores de tenacidade encontram-se próximos daquele obtido por Pardal et al. [31] para o processo GTAW na linha de fusão (LF), com exceção da mistura $75-25$, que mesmo no centro do metal de solda (CMS) manteve-se no mesmo patamar. Como observado na Figura 11 os valores da tenacidade no CMS foram em todos os casos inferiores aos obtidos pelos processos GTAW e SAW, entretanto os valores corrigidos assim obtidos resultaram maiores que $27 \mathrm{~J}$, cujo valor é o mínimo requerido pela norma NORSOK M 601 [29]. Um comportamento similar é observado para misturas ternárias da Figura 12 onde apenas a mistura 78-20-2 denota valores de tenacidade baixos tanto na LF quanto no CMS. Entretanto, todos os valores assim obtidos se encontram acima do valor crítico de $27 \mathrm{~J}$. Em geral, os menores valores aqui apresentados em comparação com o processo GTAW são principalmente consequência das inclusões oriundas do processo de soldagem empregado neste trabalho. Neste sentido, a Figura 13

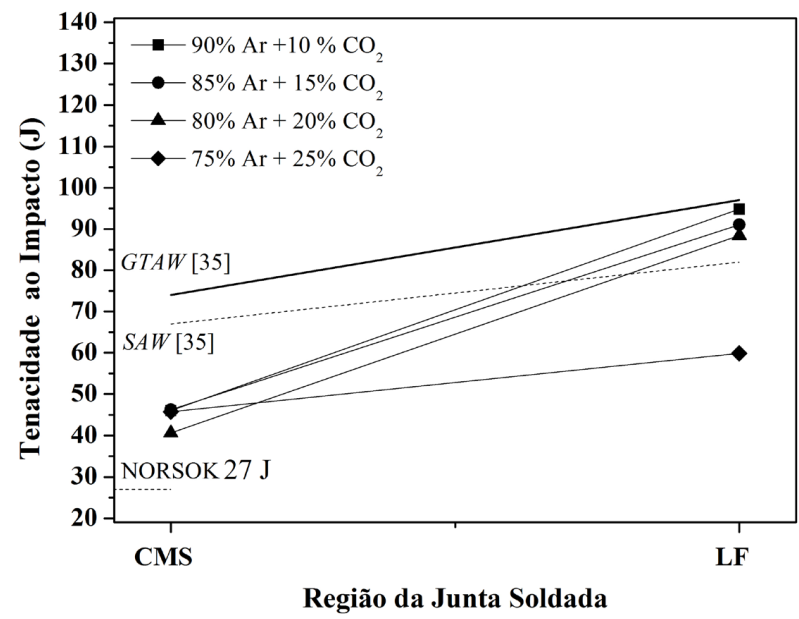

Figura 11. Valores de tenacidade ao impacto por local da junta soldada em função do teor de $\mathrm{CO}_{2}$ para misturas binárias (100-X)\% $\mathrm{Ar}+\mathrm{X} \% \mathrm{CO}_{2}$. Comparativo com os processos GTAW e SAW. 
mostra o aspecto da fratura e a superfície lateral do corpo de prova que apresentou uma dos menores valores de tenacidade. Na Figura 13a observa-se uma superfície de fratura contendo finas bordas cisalhantes emoldurando o corpo de prova com uma visível expansão lateral no mesmo, ao passo que na Figura 13b se denotam sinais de deformação plástica na região do impacto do pêndulo. Estes fatos dão suficientes indícios que a fratura não foi completamente frágil.

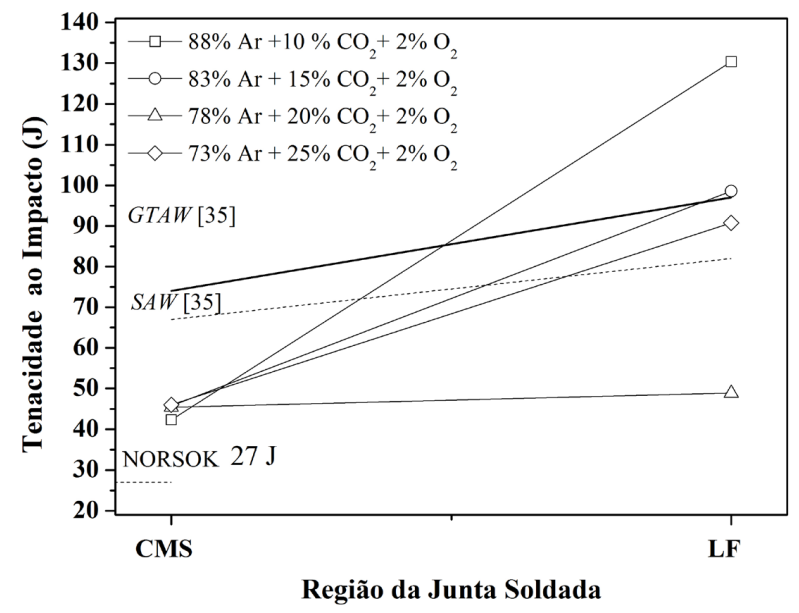

Figura 12. Valores de tenacidade ao impacto por local da junta soldada em função do teor de $\mathrm{CO}_{2}$ para misturas ternarias $(100-\mathrm{X}-2) \% \mathrm{Ar}+\mathrm{X} \% \mathrm{CO}_{2}+2 \% \mathrm{O}_{2}$. Comparativo com os processos GTAW e SAW.
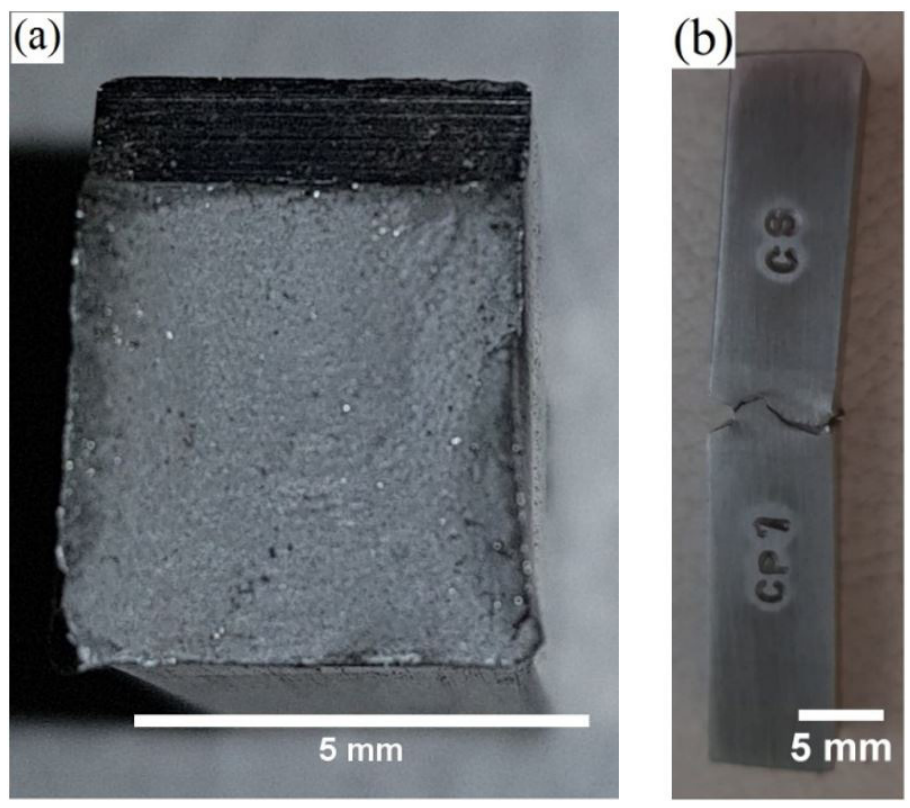

Figura 13. Imagens resultante após a fratura do corpo de prova 80-20. (a) Aspecto da superfície fratura; (b) Aspecto da superfície lateral.

As Figuras 14 e 15 apresentam o comportamento da temperatura crítica de pite (CPT) para as juntas soldadas com os gases de proteção utilizados neste trabalho. A análise das figuras revela que os valores de CPT não apresentam diferenças substanciais com o incremento de $\mathrm{CO}_{2}$ no gás de proteção. Entretanto, os valores da CPT são maiores na raiz quando comparados com a região de acabamento da junta em virtude de se obterem percentuais de ferrita e austenita similares contribuindo, desse modo, a partição adequada de elementos de liga em ambas as fases que resultam em valores de CPT próximos de cada fase próximos. Assim, o comportamento verificado no acabamento é produto de uma diferença de partição de elementos, tais como $\mathrm{Cr}$ e Mo, que afetam 


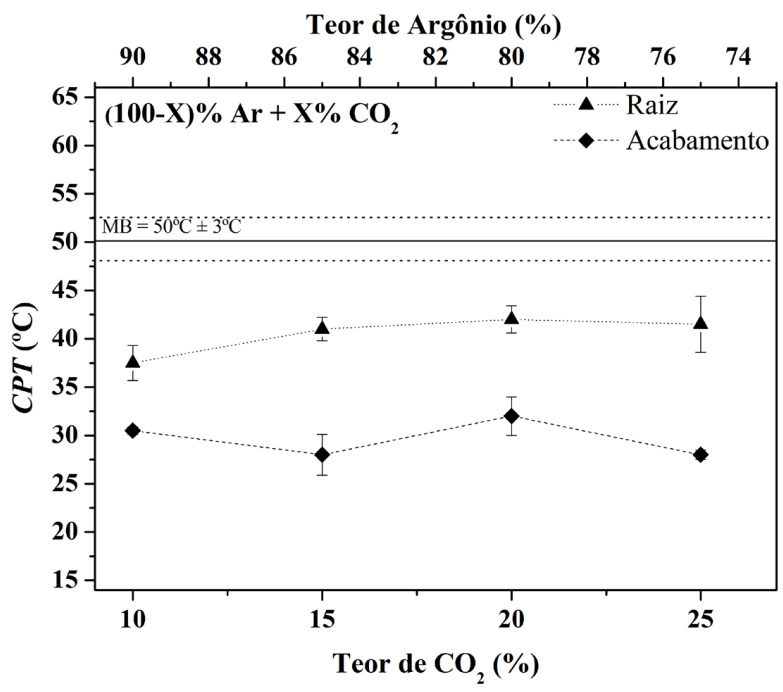

Figura 14. Valores da CPT por região do $\mathrm{MS}$ em função do teor de $\mathrm{CO}_{2}$ em misturas binárias $(100-\mathrm{X}) \% \mathrm{Ar}+\mathrm{X} \% \mathrm{CO}_{2}$ comparados com o valor do metal de base.

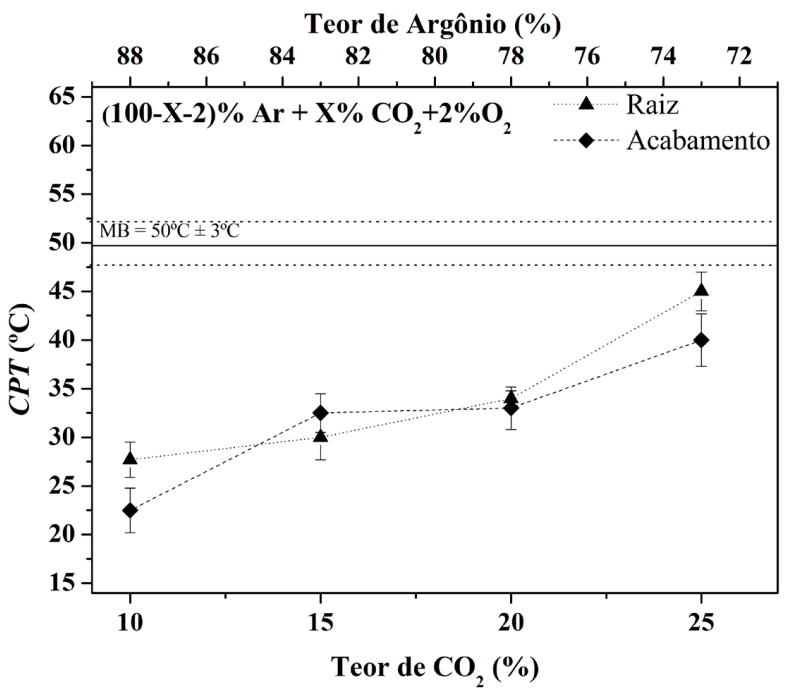

Figura 15. Valores da CPT por região do MS em função do teor de $\mathrm{CO}_{2}$ em misturas ternárias (100-X-2) $\% \mathrm{Ar}+\mathrm{X} \% \mathrm{CO}_{2}+2 \% \mathrm{O}_{2}$. Comparativo com o MB.

a resistência à corrosão de uma das fases. Contudo, ressalta-se que os valores de aporte de calor utilizados na soldagem da raiz e do acabamento atenderam, em ambos os casos, os limites recomendados [14,15]. No que diz respeito à adição de $\mathrm{O}_{2}$, não se observa uma influência tão significativa no comportamento dos valores da $C P T$ entre a raiz e o acabamento das juntas avaliadas, embora se atente para um efeito benéfico desta propriedade para a condição 73-25-2, onde se obteve um valor de CPT na raiz de aproximadamente $90 \%$ do metal de base.

Na Figura 16 observa-se o comportamento da resistência à corrosão pelo ensaio de perda de massa para as juntas soldadas com os gases de proteção estudados neste trabalho. Analisando-se a Figura 16 se observa que para o gás de proteção sem a adição de $\mathrm{O}_{2}$, a perda de massa aumenta com o aumento do teor de $\mathrm{CO}_{2}$. Por outro lado, para o gás contendo $\mathrm{O}_{2}$, a perda de massa foi menor com o aumento da quantidade de $\mathrm{CO}_{2}$. Entretanto, ressalta-se que independentemente da mistura empregada os valores de perda de massa se encontram acima do especificado como valor mínimo pela ASTM G48 [28], o que indica o alto rigor do critério de aceitação adotado por esta norma.

Avaliando-se a Figura 16, o comportamento da resistência à corrosão que diminui com o aumento do teor de $\mathrm{CO}_{2}$, pode ser explicado pelo fato de que quanto maior o teor de $\mathrm{CO}_{2}$ maior é a condutividade térmica e, 


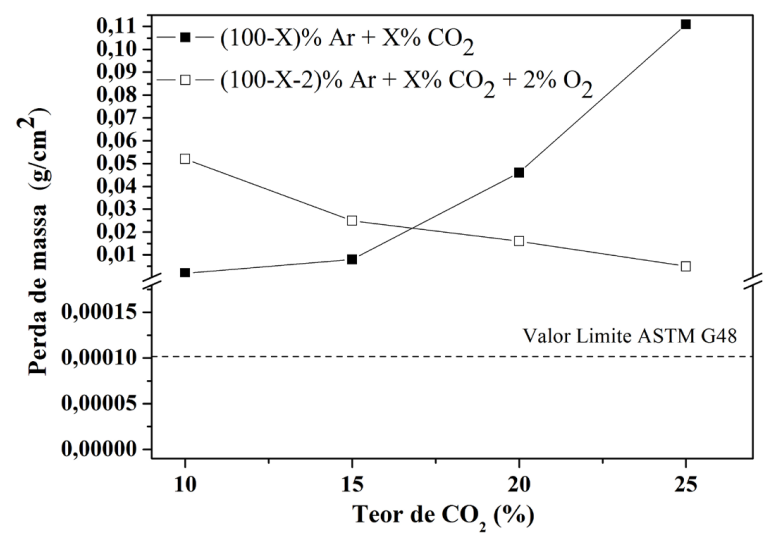

Figura 16. Valores da perda de massa em função do teor de $\mathrm{CO}_{2}$ em misturas binárias $(100-\mathrm{X}) \% \mathrm{Ar}+\mathrm{X} \% \mathrm{CO}_{2} \mathrm{e}$ ternarias $(100-\mathrm{X}-2) \% \mathrm{Ar}+\mathrm{X} \% \mathrm{CO}_{2}+2 \% \mathrm{O}_{2}$.

consequentemente, maior o aporte de calor. Este fato afeta a energia de soldagem na poça de fusão e a transferência metálica provocando inclusões de escórias grosseiras na amostra onde se utilizou o gás de proteção com $25 \% \mathrm{CO}_{2}$ se comparada com aquela produzida com a mistura com $10 \% \mathrm{CO}_{2}$, tal como observado, respectivamente, nas Figuras 17 e 18 em superfícies de amostras reveladas microestruturalmente logo após de realizado o ensaio de imersão em cloreto férrico. Nestes casos, as inclusões atuam como sítios nucleadores de pites na sua interface com a matriz. Finalmente, conforme mencionado por Sathiya et al. [14] a soldagem com adição de $\mathrm{O}_{2}$ apresentou comparativamente uma maior resistência à corrosão atribuída à presença de $\mathrm{O}_{2}$, cuja presença diminui a tensão superficial do metal fundido, minimizando a quantidade e o tamanho das inclusões de escória advindas do processo de soldagem.

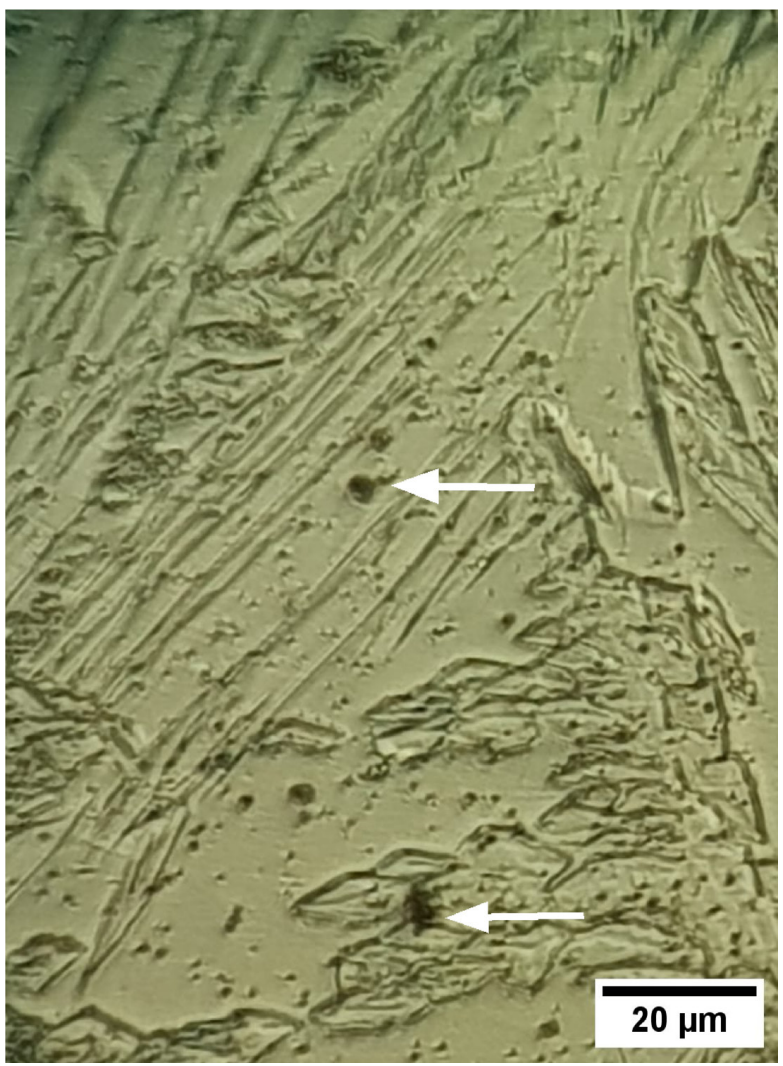

Figura 17. Pequenas inclusões na superfície da amostra na condição 90-10 após de realizado o ensaio de imersão em cloreto férrico. 


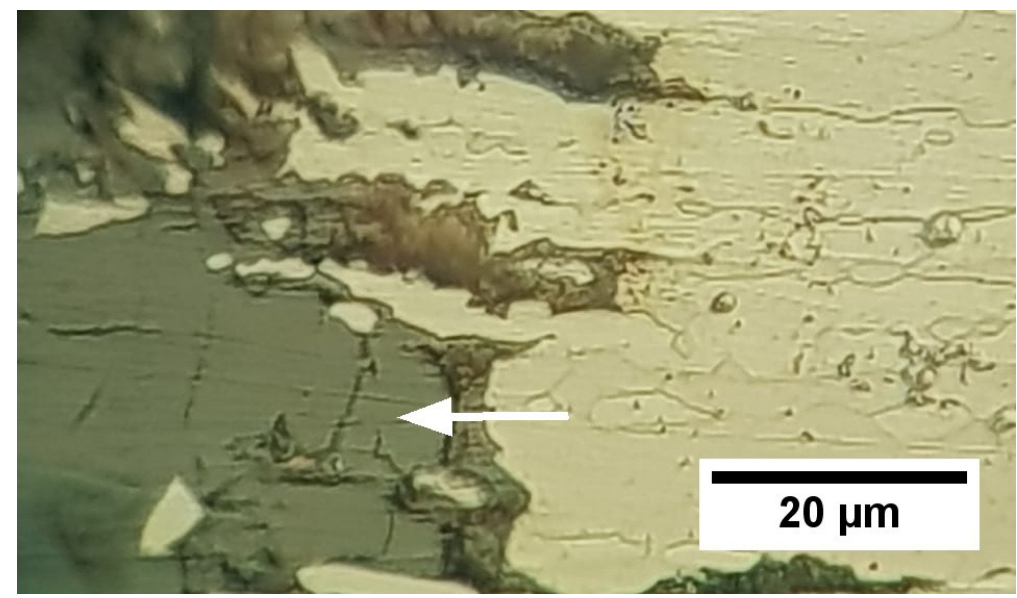

Figura 18. Inclusões grosseiras na superfície da amostra na condição 75-25 após de realizado o ensaio de imersão em cloreto férrico.

\section{Conclusões}

O presente trabalho, que teve como objetivo o estudo da influência dos gases de proteção nas propriedades mecânicas e de resistência à corrosão na soldagem do aço inoxidável duplex UNS S31803 pelos processos FCAW, permite as seguintes conclusões:

1. Embora os valores do teor de ferrita tenham ficado elevados quando comparados ao metal de base, não foi evidenciada uma influência significativa em função das misturas binárias e ternárias utilizadas neste trabalho que impactem no desempenho mecânico e na resistência à corrosão das juntas soldadas com os gases utilizados;

2. No que diz respeitos aos valores de microdureza observa-se, em geral, no metal de solda, um comportamento próximo ao do metal de base, tanto da ferrita, quanto da austenita, embora se observou um pico isolado desta propriedade para a mistura contendo $75 \%$ de argônio e $25 \%$ de $\mathrm{CO}_{2}$ que deve ser estudado com mais detalhe;

3. Não se detectou a influência dos gases de proteção empregados nas propriedades mecânicas resultantes do ensaio de tração, sendo que em todos os casos as fraturas ocorreram no metal de base;

4. Os valores de tenacidade ao impacto foram, em todos os casos, superiores a $27 \mathrm{~J}$ na temperatura de $-46^{\circ} \mathrm{C}$. Entretanto, a queda da tenacidade em relação ao processo GTAW foi atribuída apenas às inclusões advindas do fluxo do consumível de soldagem utilizado;

5. Os valores da temperatura crítica de pites (CPT) das juntas soldadas produzidas em função da composição do gás foram inferiores ao metal de base. Verificou-se que na condição de soldagem se utilizando como gás

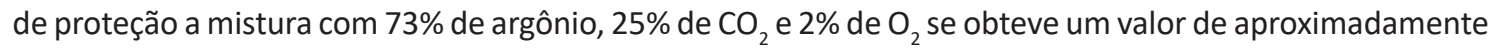
$90 \%$ do valor alcançado no metal de base;

6. Apesar de não satisfazer os requisitos estabelecidos pela metodologia A da ASTM G48, observou-se uma forte influência da composição do gás na perda de massa, onde apenas a adição de $\mathrm{CO}_{2}$ exerce um efeito prejudicial na resistência à corrosão. Entretanto, quando se adiciona $2 \%$ de $\mathrm{O}_{2}$ ao gás de proteção, se verifica um comportamento oposto, o qual pode ser atribuído à diminuição da quantidade e tamanho de inclusões não metálicas as quais se comportam como locais de formação de pites;

7. Os procedimentos de soldagem utilizados nas juntas soldadas estudadas atendem aos requisitos para a resistência mecânica previstos no código ASME SEÇÃO IX;

8. A junta soldada produzida com o gás de proteção cuja composição é $73 \%$ Argônio $+25 \% \mathrm{CO}_{2}+2 \% \mathrm{O}_{2}$ apresentou o melhor desempenho, tanto no que diz respeito às propriedades mecânicas, quanto na resistência à corrosão. 


\section{Referências}

[1] Pardal JM. Aços inoxidáveis superduplex: efeito dos tratamentos térmicos nas propriedades mecânicas, magnéticos e resistência à corrosão. 1. ed. São Paulo: Blucher; 2012.

[2] Gunn RN. Duplex stainless steels: microstructure, properties and applications. Cambridge: Abington Publishing; 1997. http:// dx.doi.org/10.1533/9781845698775.

[3] Muthupandi V, Bala Srinivasan P, Seshadri SK, Sundaresan S. Effect of weld metal chemistry and heat input on the structure and properties of duplex stainless steel welds. Materials Science and Engineering A. 2003;358(1-2):9-16. http://dx.doi. org/10.1016/S0921-5093(03)00077-7.

[4] Tavares SSM, Pardal JM, Lima LD, Bastos IN, Nascimento AM, Souza JA. Characterization of microstructure, chemical composition, corrosion resistance and toughness of a multipass weld joint of superduplex stainless steel UNS S32750. Materials Characterization. 2007;58(7):610-616. http://dx.doi.org/10.1016/j. matchar.2006.07.006.

[5] Souza GC, Silva AL, Tavares SSM, Pardal JM, Ferreira MLR, Cardote I Fo. Avaliação das propriedades mecânicas e da resistência à corrosão em soldas de reparo pelo processo GTAW no aço inoxidável superduplex UNS S32760. Soldagem e Inspeção. 2014;19(4):302-313. http://dx.doi.org/10.1590/0104-9224/ SI1904.03.

[6] Paiva TCC, Martins TRB, Souza GC, Pardal JM, Tavares SSM, Fonseca MC, et al. Análise da influência do gás de purga na raiz de juntas soldadas pelo processo GTAW em aço inoxidável superduplex UNS S32750. Soldagem e Inspeção. 2014;19(2):125133. http://dx.doi.org/10.1590/0104-9224/SI1902.04.

[7] Alvarez TR, Pavarino MRC, Souza GC, Pardal JM, Tavares SSM, Ferreira ML, et al. Influência da temperatura interpasse nas propriedades do aço inoxidável duplex durante a soldagem pelo processo a arco submerso. Soldagem e Inspeção. 2014;19(2):114124. http://dx.doi.org/10.1590/0104-9224/SI1902.03.

[8] Cardoso R Jr, Bracarense AQ, Campos FR, Souza CS, Silveira DM, Lins VFC. Avaliação da soldagem multipasse de chapas espessas de aços inoxidáveis lean duplex UNS S32304 soldadas pelos processos SMAW, GMAW e FCAW. Parte 1: propriedades mecânicas. Soldagem e Inspeção. 2012;17(4):306-316. http:// dx.doi.org/10.1590/S0104-92242012000400005.

[9] Mukhopadhyay S, Pal TK. Effect of shielding gas mixture on gas metal arc welding of HSLA steel using solid and flux-cored wires. International Journal of Advanced Manufacturing Technology. 2006;29(3-4):262-268. http://dx.doi.org/10.1007/s00170-0052510-7.

[10] Sieurin H, Sandström R. Sigma phase precipitation in duplex stainless steel 2205. Materials Science and Engineering A. 2007;444(12):271-276. http://dx.doi.org/10.1016/j.msea.2006.08.107.

[11] Michalska J, Sozańska M. Qualitative and quantitative analysis of $\sigma$ and $\chi$ phases in 2205 duplex stainless steel. Materials Characterization. 2006;56(4-5):355-362. http://dx.doi. org/10.1016/j.matchar.2005.11.003.

[12] Verma J, Taiwade V. Effect of welding processes and conditions on the microstructure, mechanical properties and corrosion resistance of duplex stainless steel weldments: a review. Journal of Manufacturing Processes. 2017;25:134-152. http://dx.doi. org/10.1016/j.jmapro.2016.11.003.

[13] Zhang Z, Wang Z, Jiang Y, Tan H, Han D, Guo Y, et al. Effect of post-weld heat treatment on microstructure evolution and pitting corrosion behavior of UNS S31803 duplex stainless steel welds. Corrosion Science. 2012;62:42-50. http://dx.doi. org/10.1016/j.corsci.2012.04.047.
[14] Sathiya P, Aravindan S, Soundararajan R, Noorul Haq A. Effect of shielding gases on mechanical and metallurgical properties of duplex stainless-steel welds. Journal of Materials Science. 2009;44(1):114-121. http://dx.doi.org/10.1007/s10853-0083098-8.

[15] Jang S-H, Kim S-T, Lee I-S, Park Y-S. Effect of shielding gas composition on phase transformation and mechanism of pitting corrosion of hyper duplex stainless welds. Materials Transactions. 2011;52(6):1228-1236. http://dx.doi.org/10.2320/ matertrans.M2010414.

[16] Garcia RP, Scotti A. Análise comparativa da geração de fumos entre arames maciços (GMAW) e tubulares (FCAW). Soldagem e Inspeção. 2010;15(2):103-111. http://dx.doi.org/10.1590/ S0104-92242010000200004.

[17] Jönsson PG, Murphy AB, Szekely J. The influence of oxygen additions on argon-shielded gas metal arc welding processes. Welding Journal. 1995;74(2):48-58.

[18] Starling CMD, Modenesi PJ, Borba TMD. Caracterização do cordão na soldagem FCAW com um arame tubular "Metal Cored". Soldagem e Inspeção. 2011;16(3):285-300. http:// dx.doi.org/10.1590/S0104-92242011000300010.

[19] Kah P, Martikainen J. Influence of shielding gases in the welding of metals. International Journal of Advanced Manufacturing Technology. 2013;64(9-12):1411-1421. http://dx.doi.org/10.1007/ s00170-012-4111-6.

[20] Liao MT, Chen WJ. The effect of shielding gas compositions on the microstructure and mechanical properties of stainless steel weldments. Materials Chemistry and Physics. 1998;55(2):145151. http://dx.doi.org/10.1016/S0254-0584(98)00134-5.

[21] Tatagiba LCS, Gonçalves RB, Paranhos R. Tendências no desenvolvimento de gases de proteção utilizados na soldagem MIG/MAG. Soldagem e Inspeção. 2012;17(3):218-228. http:// dx.doi.org/10.1590/S0104-92242012000300006.

[22] American Welding Society. AWS A5.32/A5.32M:2011: welding consumables and gas mixtures for fusion welding and allied processes. Miami: AWS; 2011. 29 p.

[23] Pettersson CO, Fager, SA. Welding practice for the sandvik duplex stainless steels SAF 2304, SAF 2205 and SAF 2507. Sandviken: AB Sandvik Steel.

[24] American Society of Mechanical Engineers. ASME IX -2007: welding and brazing qualifications. New York: ASME; 2007.

[25] Suban M, Tusek J. Dependence of melting rate in MIG/MAG welding on the type of shielding gas used. Journal of Materials Processing Technology. 2001;119(1-3):185-192. http://dx.doi. org/10.1016/S0924-0136(01)00940-2.

[26] University of Texas Health Science Center. Department of Dental Diagnostic Science. Image Tool Version 3.0. San Antonio: UTHSCSA; 2010 [acesso em 8 dez. 2010]. Disponível em: http:// ddsdx.uthscsa.edu/dig/itdesc.html

[27] American Society for Testing and Materials. ASTM G150-99: standard test method for electrochemical critical pitting temperature testing of stainless steels. West Conshohocken: ASTM; 1999.

[28] American Society for Testing and Materials. ASTM G48-03 (reapproved 2009): standard test methods for pitting and crevice corrosion resistance of stainless steels and related alloys by use of ferric chloride solution. West Conshohocken: ASTM; 2003. 
Influência dos Gases de Proteção na Soldagem do Aço UNS S31803 com Arame E2209-T1/4 pelo Processo FCAW

[29] Standards Norway. Norsok standard M-601: welding and inspection of piping. Lysaker: Standards Norway; 2004.

[30] American Society for Testing and Materials. ASTM A370-17a: standard test methods and definitions for mechanical testing of steel products. West Conshohocken: ASTM; 2017
[31] Pardal JM, Souza GC, Tavares SSM, Fonseca MPC, Ferreira MLR, Martins LM, et al. Caracterização e avaliação da resistência à corrosão na soldagem de tubulação de aço inoxidável duplex uns s31803 pelo processo a arco submerso. Soldagem e Inspeção. 2011;16(4):310-321. http://dx.doi.org/10.1590/ S0104-92242011000400002. 